Research Article

\title{
Experimental Study on the Mechanical Properties of Sandstone under the Action of Chemical Erosion and Freeze-Thaw Cycles
}

\author{
Lizhuang Cui, ${ }^{1}$ Nan Qin $\mathbb{i D}^{1,2,3}$ Shuai Wang ${ }^{10},{ }^{1,2}$ and Xuezhi Feng ${ }^{1}$ \\ ${ }^{1}$ School of Mechanical and Electrical Engineering, Qingdao University of Science and Technology, Qingdao 266061, China \\ ${ }^{2}$ State Key Laboratory of Coal Resources and Safe Mining, China University of Mining and Technology, XuZhou 221116, China \\ ${ }^{3}$ Key Laboratory of Mine Disaster Prevention and Control of the Ministry of Education, \\ Shandong University of Science and Technology, Qingdao 266590, China
}

Correspondence should be addressed to Nan Qin; qinnan_qust@126.com and Shuai Wang; wsh0509@126.com

Received 21 July 2020; Revised 6 January 2021; Accepted 18 February 2021; Published 1 March 2021

Academic Editor: Jia-wen Zhou

Copyright (C) 2021 Lizhuang Cui et al. This is an open access article distributed under the Creative Commons Attribution License, which permits unrestricted use, distribution, and reproduction in any medium, provided the original work is properly cited.

\begin{abstract}
In order to study the mechanical properties of sandstone under the coupling action of chemical erosion and freeze-thaw cycles, the fine-grained yellow sandstone in a mining area in Zigong, China, is collected as the research object. The changes in mechanical properties of yellow sandstone under the coupling action of chemical solution erosion and freeze-thaw cycles are analyzed based on uniaxial compression tests (UCTs) and triaxial compression tests (TCTs). The results show that, with the increase in freezethaw cycles, the compressive strength, elastic modulus, and cohesion of the sandstone samples decrease with varying degrees. Under constant freeze-thaw cycles, the most serious mechanical properties of degradation are observed in acidic solution, followed by alkaline solution and neutral solution. Under different confining pressures, the compressive strength and elastic modulus of the sandstone samples decrease exponentially with the increase in freeze-thaw cycles. Under the action of the chemical solution erosion and freeze-thaw cycles, the internal friction angle fluctuates around $30^{\circ}$. For the cohesion degradation, $35.4 \%$, $29.3 \%$, and $27.2 \%$ degradation are observed under acidic, alkaline, and neutral solutions. Nuclear magnetic resonance imaging shows that the chemical erosion and freeze-thaw cycles both promote the degradation of rock properties from surface to interior; after 45 freeze-thaw cycles, the mechanical properties drop sharply. To properly design rock tunneling support and long-term protection in the cold region, the impact of both freeze-thaw cycles and chemical erosion should be considered.
\end{abstract}

\section{Introduction}

The subsurface works in the western part of China is not only affected by the low temperature environment and freezethaw cycles but also influenced by factors such as acid rain and groundwater erosion. Not only hydrochemical reaction causes elements to redistribute between rocks and water [1], the volume expansion of water in the pores will also produce freezing force during the freeze-thaw cycles $[2,3]$. The freezing force leads to the expansion of the original defect and the generation and expansion of new cracks, which cause imbalances within its soil particles, water molecules, and ions and decrease in strength and increase in compressibility. This will further accelerate the damage and destruction of rock and eventually lead to the degradation in its mechanical properties, which will affect the service life and investment benefits of rock engineering [4-6]. Therefore, the study on the change in mechanical properties of sandstone under the coupling action of chemical erosion and freeze-thaw cycles has guiding significance for the construction and protection of actual geotechnical engineering.

The mechanical properties of rock under freeze-thaw cycles have been studied by many researchers. Ni et al. carried out triaxial unloading tests on tunnel sandstone in the cold area after different cycles and obtained the whole stress-strain curve, peak strength, and microstructure morphology characteristics after freeze-thaw cycles [7]. Wang et al. conducted mechanical tests on intact quartzite 
after freeze-thaw cycles and obtained physical parameters and triaxial compression mechanical properties of quartzite [8]. Park et al. carried out laboratory experiments for the measurement of the specific heat, thermal conductivity, and thermal expansion coefficient in the temperature range of $-160^{\circ} \mathrm{C}$ to $40^{\circ} \mathrm{C}$, and the results were utilized for the evaluation of thermal propagation in rock mass and the thermomechanical stability of underground facilities [9]. Similar experiments have been conducted [10-14]. Li et al. established a limestone chemical corrosion model and analyzed the mechanical properties of limestone [15]. Han et al. conducted quantitative studies on microstructure damage of sandstone after water chemical erosion [16]. Feng et al. studied the damage evolution mechanism of sandstone in $\mathrm{NaCl}, \mathrm{CaCl}_{2}$, and $\mathrm{Na}_{2} \mathrm{CO}_{3}$ solutions [17]. Han et al. studied the mechanical properties of granite in strong acid and strong alkali solution and found out the damage mechanism of granite [18]. Atkinson and Meredith investigated the influence of different chemical solutions on the strength and crack propagation rate of quartz and found that increasing environmental $\mathrm{OH}^{-}$concentration resulted in a faster expansion rate of the quartz fracture by means of a crack propagation model [19]. Similar scientific research has been conducted $[20,21]$.

However, the coupling actions of chemical erosion and freeze-thaw cycles were not considered in their studies. In geotechnical engineering, the rock mass structure is subjected to strong coupled freeze-thaw cycles. An understanding of the interplays between these different processes demands a comprehensive study of the fully coupled behaviour which is crucial for a reliable and cost-effective design rock tunneling support and long-term protection. Xu et al. investigated the coupling effects of chemical corrosion and freeze-thaw cycles on the physical and mechanical properties of tonalite samples. However, the research only considered the erosion under acidic conditions and did not consider the influence of confining pressure [22]. The mine rocks in the western part of China are affected by chemical erosion and freeze-thaw cycles, and few research studies have been reported on the mechanical properties of rocks under the combined action of the two factors. In the present paper, the fine-grained yellow sandstone in the underground mines in Zigong, China, is used as the experimental object, and UCT, TCT, and mesodamage monitoring of the yellow sandstone under the coupling effects of chemical and freezethaw cycles are carried out.

\section{Materials and Methods}

2.1. Sample Preparation. The samples were fine-grained yellow mine sandstone collected from Zigong, China. The mineral compositions of the samples were obtained based on an X-ray diffraction (XRD) analysis and are presented in Table 1. The tests were completed under the guidance of the "Standard for Test Methods of Engineering Rock Mass" (GB/ $\mathrm{T}$ 50266-2013) [23]. The samples were processed into cylinders with a diameter of $50 \mathrm{~mm}$ and a height of $100 \mathrm{~mm}$ (Figure 1). This is in line with the recommendations of the International Society for Rock Mechanics (ISRM). To ensure the homogeneity of the sandstone samples, the NN-4B nonmetal ultrasonic detection analyser is used for acoustic wave detection. After removing the samples with large acoustic wave difference, the remaining ones with consistent mechanical properties were chosen. Note that the average value of longitudinal wave velocity was $2.5 \mathrm{~km} / \mathrm{s}$. The samples were divided into 3 groups with 15 samples in each group. At least, 3 parallel tests were conducted for each group.

Samples were then placed in the constant temperaturehumidity container under a constant temperature of $105^{\circ} \mathrm{C}$ and dried for $48 \mathrm{~h}$. Then, samples were weighed, and the data were recorded. The samples under different chemical solutions were saturated by an MP-VPS vacuum saturation device, and the quality of every saturated sample was recorded. The average density of the samples was $1.94 \sim 1.98 \mathrm{~g} / \mathrm{cm}^{3}$, and the porosity was $15.6 \% \sim 20.4 \%$.

2.2. Experimental Devices and Test Process Design. The freeze-thaw cycle equipment used in the test is the constant temperature-humidity chamber (Figure 2). The equipment is controlled by Proportional Integral Derivative (PID), which can realize functions such as refrigeration and heating. Temperature control scope is from $-40^{\circ} \mathrm{C}$ to $150^{\circ} \mathrm{C}$, with an accuracy of $\pm 0.1^{\circ} \mathrm{C}$. A series of UCT and TCT were conducted using the TAW-200 electronic multifunctional material mechanics testing machine. The machine is developed by Qingdao University of Science and Technology and Changchun Chaoyang Testing Machine Factory (Figure 3) and has two loading modes: force and displacement control. The maximum axial pressure is $200 \mathrm{kN}$ with an accuracy of $\pm 1 \mathrm{kN}$, and the maximum confining pressure is $30 \mathrm{MPa}$ with a precision of $\pm 0.1 \mathrm{MPa}$. In the test, a loading rate of $50 \mathrm{~N} / \mathrm{s}$ was applied.

The samples cross section imaging analysis was conducted using the MacroMR12-150H-I Low Field Nuclear Magnetic Resonance Analysis System produced by Suzhou Niumag Analytical Instrument Corporation. The instrument is shown in Figure 4.

The test process was as follows: (1) the $\mathrm{NaCl}$ solution with an initial concentration of $0.01 \mathrm{~mol} / \mathrm{L}$ was used as base solution. An appropriate amount of $\mathrm{H}_{2} \mathrm{SO}_{4}$ and $\mathrm{NaOH}$ was added to the solution to form the $\mathrm{H}_{2} \mathrm{SO}_{4}$ acidic solution $(0.01 \mathrm{~mol} / \mathrm{L})$ and $\mathrm{NaOH}$ alkaline solution $(0.01 \mathrm{~mol} / \mathrm{L})$. To ensure the total number of ions in every solution, equal mass of $\mathrm{NaCl}$ was added to the neutral solution, and the $\mathrm{pH}$ of each solution was recorded. The cylindrical sandstone samples were saturated in the acidic $\mathrm{H}_{2} \mathrm{SO}_{4}$ solution $(0.01 \mathrm{~mol} / \mathrm{L}, \mathrm{pH}=3)$, alkaline $\mathrm{NaOH}(0.01 \mathrm{~mol} / \mathrm{L}, \mathrm{pH}=13)$ solution, and neutral $\mathrm{NaCl}(\mathrm{pH}=7)$ solution for three months, respectively. The $\mathrm{pH}$ and ion concentration of the solution were measured daily to ensure constant $\mathrm{pH}$ value of the solution during the test. (2) According to the actual situation of the project and the "Specifications for rock tests in water conservancy and hydroelectric engineering" (SL 264-2001) [24] and "Standard for Test Methods of Engineering Rock Mass" (GB/T 50266-2013) [23], the test process was designed as follows: first, the immersed 
TABle 1: Mineral composition of the samples used.

\begin{tabular}{lcccccc}
\hline Element/samples & Calcium feldspar & Quartz & Andesite & Hornblende & Pyroxene & Others \\
\hline Weight $(\%)$ & 68 & 18 & 3 & 3 & 2 & 6 \\
\hline
\end{tabular}

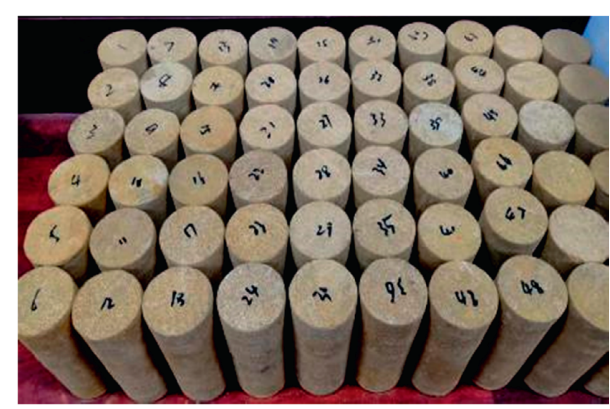

Figure 1: Part of the standard sandstone samples.

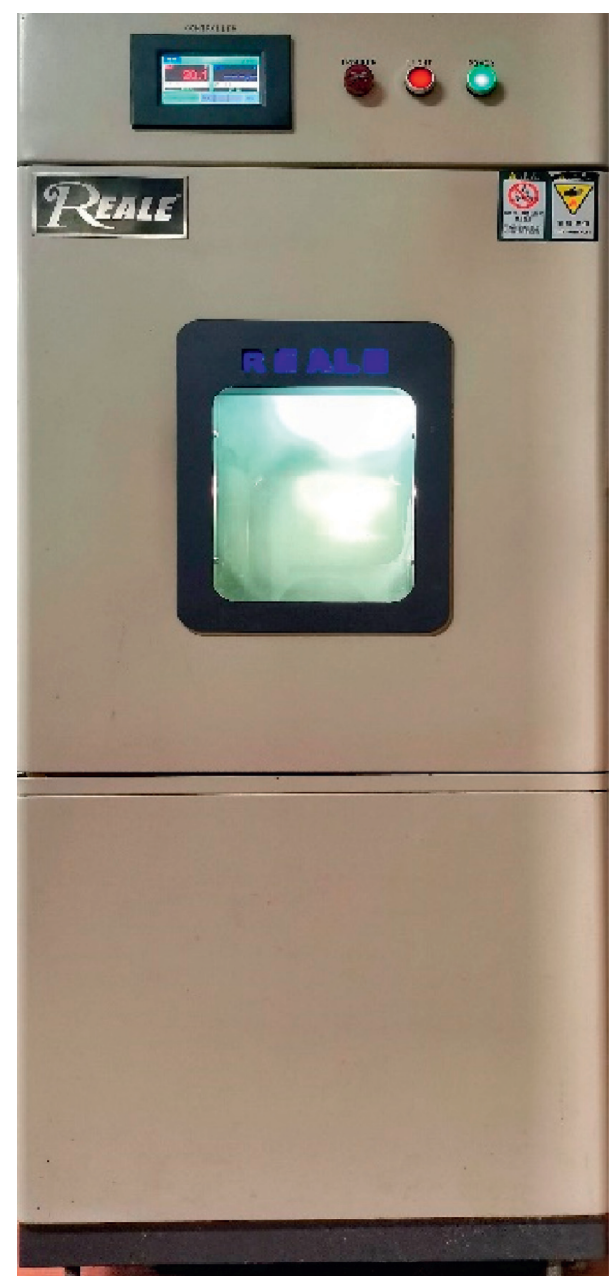

FIGURE 2: The constant temperature-humidity chamber.

sandstone samples were placed in the test container, and the freezing temperature was set to $-20^{\circ} \mathrm{C}$, and the freezing time was $12 \mathrm{~h}$. Then, the sandstone samples were placed in the corresponding chemical solution and kept at $20^{\circ} \mathrm{C}$ for $12 \mathrm{~h}$.
Each freeze-thaw cycle lasted 24 hours in total, and the freeze-thaw cycles were $0,15,30,45$, and 60 times, respectively, for the five groups of samples. After the freezethaw cycles, the mass and longitudinal wave velocity of the saturated samples were measured, and a series of nuclear magnetic imaging observation tests, UCT and TCT, were performed. The preparation work before the TCT can refer to the test operation of $\mathrm{Yu}$ et al. [25]. The actual mining depths of the local thin layer and the underground mining areas are about $120 \mathrm{~m}$ and $250 \mathrm{~m}$, respectively. According to the self-weight stress $\sigma_{z}$ of the stratum $\left(\sigma_{z}=\lambda h, \lambda\right.$ is the gravity of the rock formation), the required confining pressures are about $3 \mathrm{MPa}$ and $6 \mathrm{MPa}$, respectively.

\section{Results and Discussion}

\subsection{UCT Results and Discussion}

3.1.1. Destructive Forms of Samples. Table 2 presents the destructive forms of specimens under the coupling action of chemical solutions and freeze-thaw cycles. During the initial 30 freeze-thaw cycles, the destructive forms are vertical brittle failure and oblique shear failure. For example, the rock sample labeled " $2-0$ " produces standard longitudinal brittle failure, which is manifested by the presentation of the main crack parallel to the axial load direction. And the samples labeled "1-0," "3-0," " $2-15$," and " $3-15$ " all produce oblique shear failure, with main cracks on the sliding surface of the sandstone samples. After reaching the ultimate failure, the samples are basically complete, and the failure process is relatively stable, without the collapse of a large block. After 30 freeze-thaw cycles, the samples fail in a wedge-shaped splitting form, which is mainly manifested by wedge-shaped cracks during the failure and crushing process at the terminal face. The combined effect of freeze-thaw cycles and chemical solution erosion leads to particle softening and pore expansion inside the rock sample. As the number of freeze-thaw cycles increases, the number of cracks increases, and the degree of end-face cracking becomes more severe. The above finding is consistent with observations in Qiu et al. [26]. With the same freeze-thaw cycle, the number of the secondary cracks is the largest in acidic solution, followed by alkaline solution and neutral solution.

3.1.2. Stress-Strain Curve Results and Discussion. From the stress-strain relationship curves (Figure 5), it is easy to see that the sample deformation has experienced four stages: compaction stage $(A)$, elastic growth stage $(B)$, plastic yield stage $(C)$, and failure stage $(D)$ [27]. In the compaction section, the stress-strain relationship curve is concave because the internal pores and microcracks of the sandstone samples are gradually compacted as the load increases. Then, in the elastic growth stage, the stress-strain curve is basically linear. In the plastic yield stage, the stress-strain relationship 


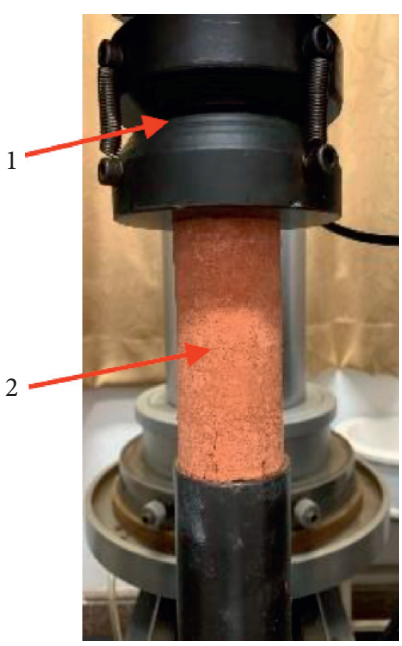

(a)

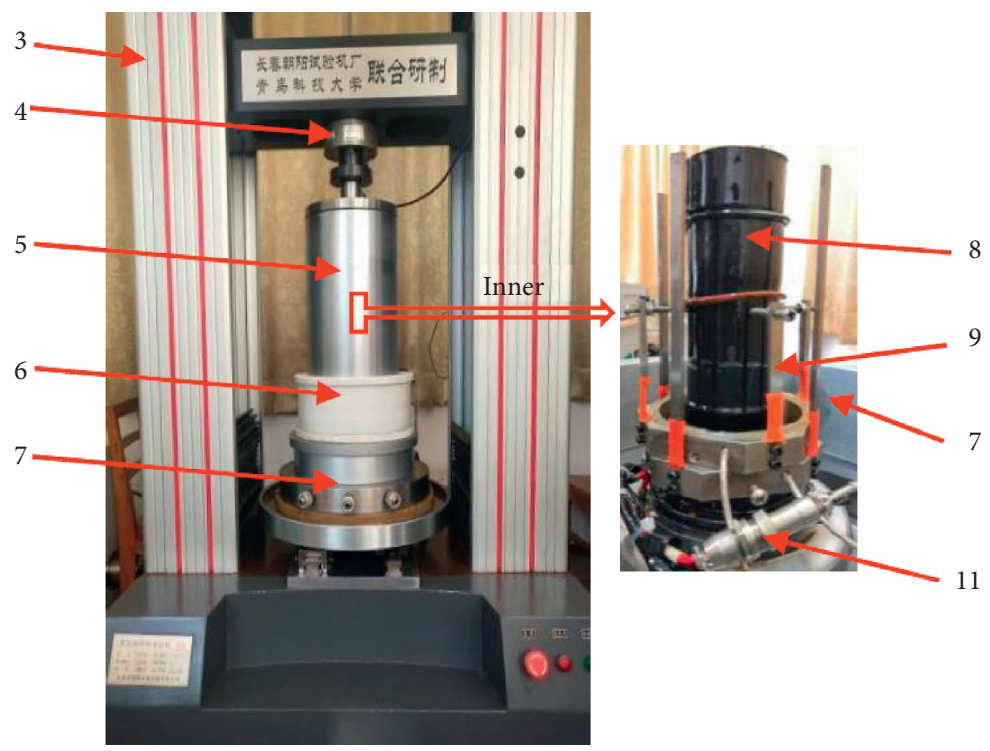

(b)

Figure 3: TAW-200 electronic multifunctional material mechanics testing machine: (a) UCT; (b) TCT. 1, press ram; 2, sandstone sample; 3 , reaction frame system; 4, pressure sensors; 5, confining pressure cylinder; 6, electromagnetic heating; 7, lantern ring; 8, heat-shrink pipe; 9 , radial displacement transducers; 11, temperature transmitter.

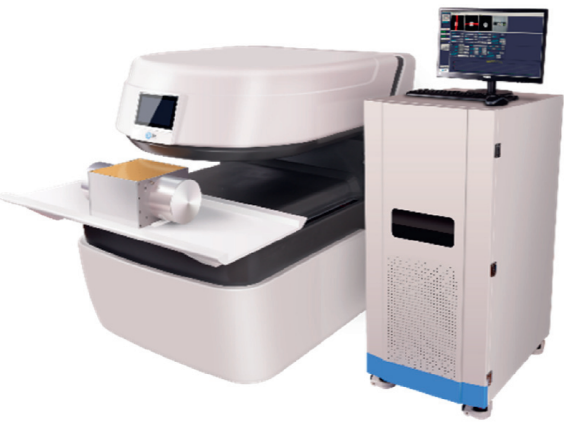

Figure 4: MacroMR12-150H-I NMR.

curve is convex; as the load increases, the internal cracks of the samples expand continuously, and the slip phenomenon among particles is more obvious; at this time, the stress reaches the maximum value. Eventually, in the failure stage, the stress value drops sharply; the main cracks appear inside and on the surface of the samples; meanwhile, the microcracks are clumped, which leads to the failure of the sample.

In the elastic growth stage, as the number of freeze-thaw cycles increases, the slope of the stress-strain relationship curve gradually decreases. Compared with freeze-thaw samples, the slope of the stress-strain relationship curve of the non-freeze-thaw samples changes significantly under acidic solution. After 45 cycles of freezing and thawing in the neutral solution, the degree of slope reduction increases. After 60 cycles of freezing and thawing in the alkaline solution, the slope of the stress-strain relationship curve decreases significantly. In the plastic yield period, the maximum stress value decreases with increasing freeze-thaw cycles under the erosion of three chemical solutions. With the same freeze- thaw cycles, the maximum stress value in the neutral solution is the largest, and it is the smallest in the acidic solution. And the difference between the maximum stress value of the neutral solution and the alkaline solution is the smallest.

3.1.3. Compressive Strength. The average compressive strength values for samples under UCT are calculated, and the uniaxial compressive strength curves of sandstone samples under chemical erosion and freeze-thaw cycles are plotted in Figure 6.

In Figure 6, it can be seen that the uniaxial compressive strengths of the sandstone samples decrease with the increase in the number of freeze-thaw cycles regardless of chemical solution types. With the same freeze-thaw cycles, the uniaxial compressive strength in the neutral solution is the largest, and it is the smallest in the acidic solution. And the difference of the uniaxial compressive strength of the neutral solution and the alkaline solution is small. 
TABLe 2: Destructive forms of specimens under the coupling action of chemical solutions and freeze-thaw cycles.

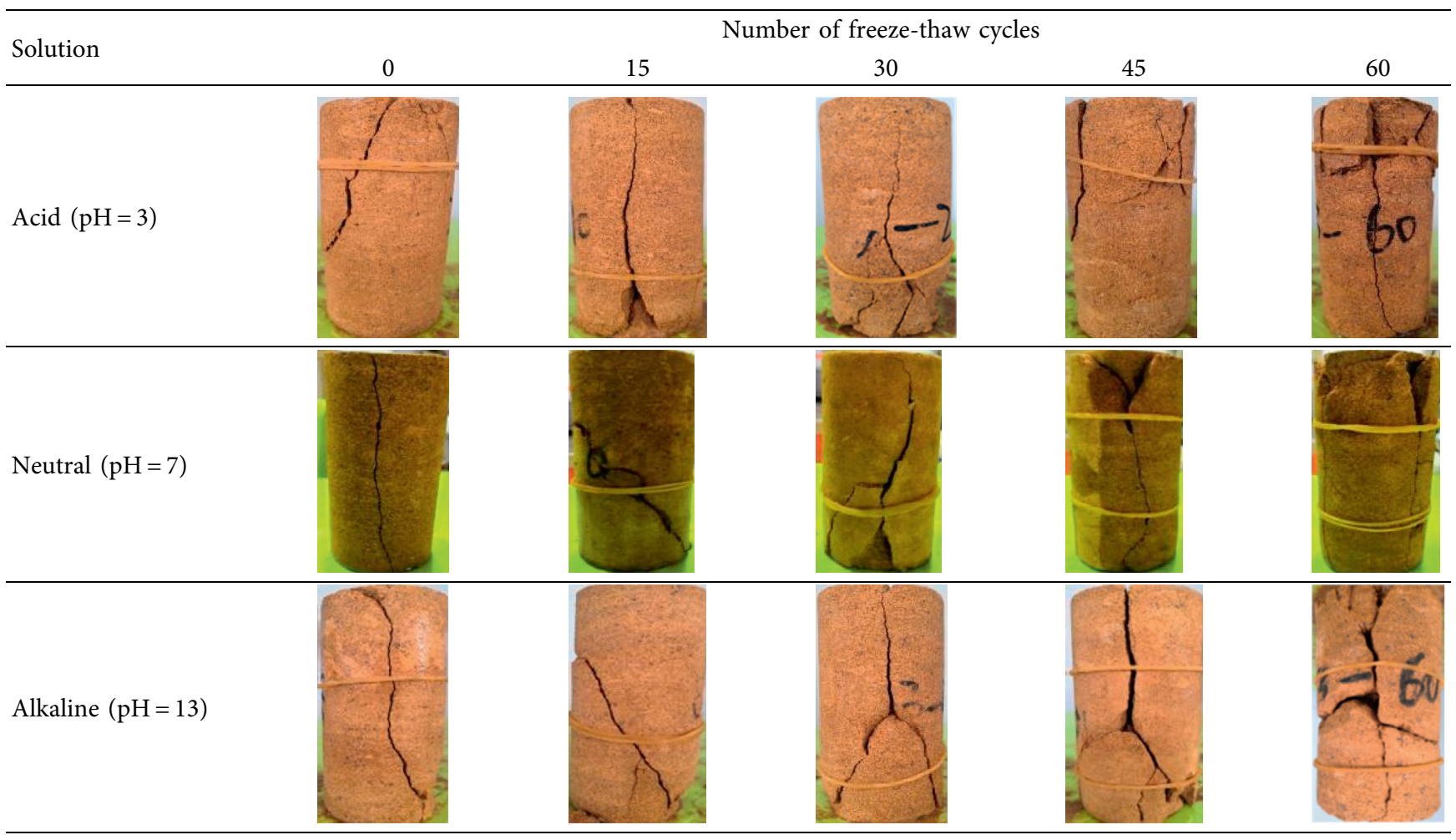

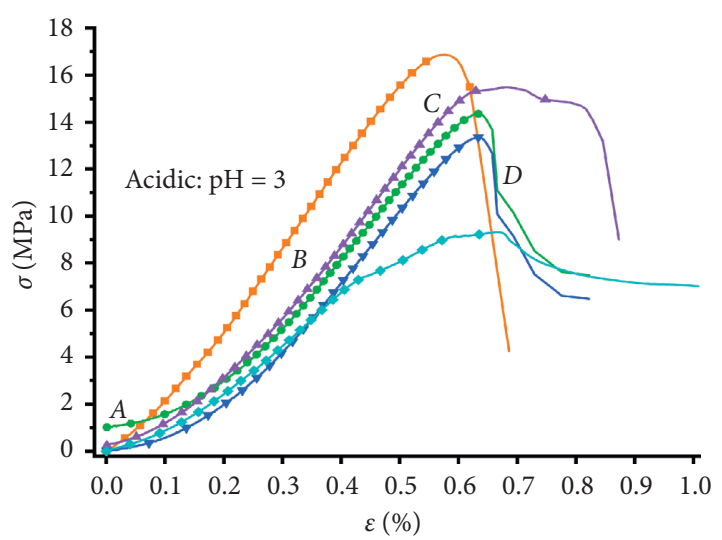

-0 F-Tc
$\multimap 15 \mathrm{~F}-\mathrm{Tc}$
$\multimap 30 \mathrm{~F}-\mathrm{Tc}$

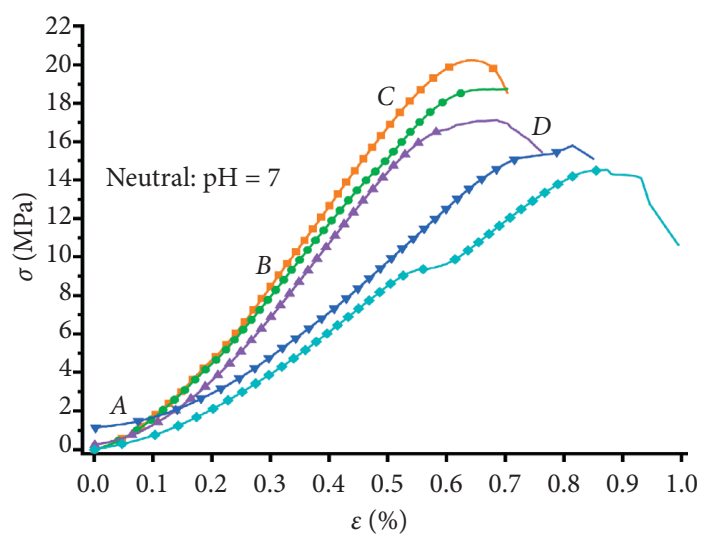

$=0 \mathrm{~F}-\mathrm{Tc}$

$\rightarrow 15 \mathrm{~F}-\mathrm{Tc}$

$\simeq 30 \mathrm{~F}-\mathrm{Tc}$ $\rightarrow 45 \mathrm{~F}-\mathrm{Tc}$

$\rightarrow 60 \mathrm{~F}-\mathrm{Tc}$

(b)

FIgURE 5: Continued. 


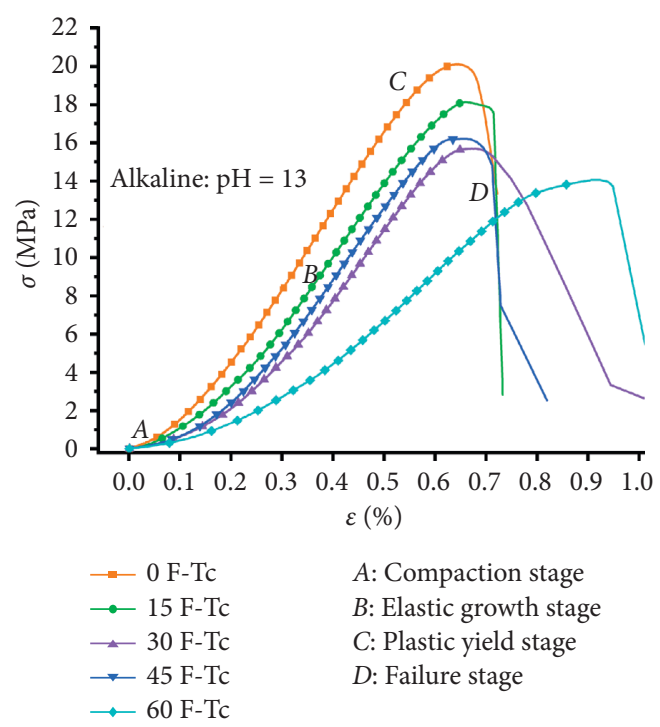

(c)

FIGURE 5: Stress-strain relationship for uniaxial compression tests after different chemical solution eroded and different number of freezethaw cycles (F-Tc): (a) uniaxial stress-strain curve under the acidic solution, $\mathrm{pH}=3$; (b) uniaxial stress-strain curve under the neutral solution, $\mathrm{pH}=7$; (c) uniaxial stress-strain curve under the alkaline solution, $\mathrm{pH}=13$.

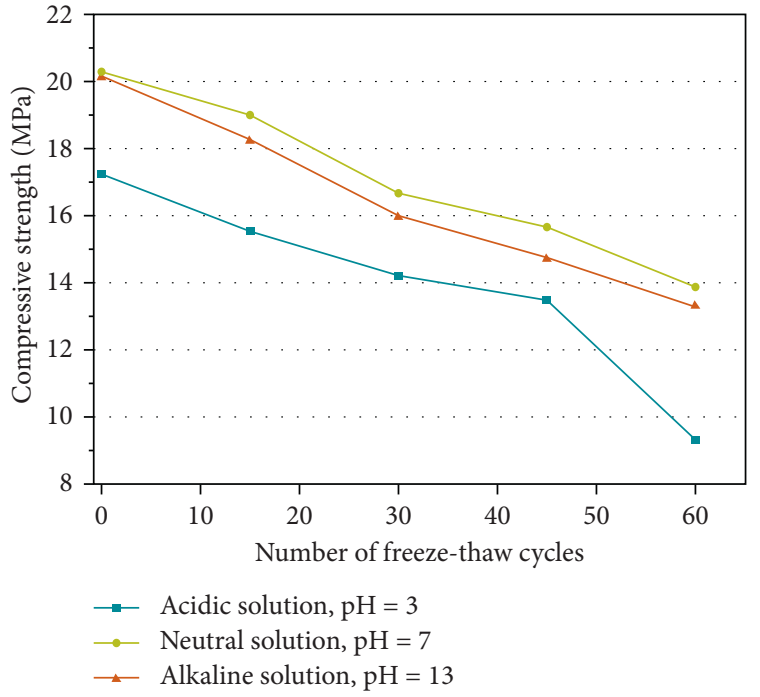

FIGURE 6: Relationship curves between the compressive strength of sandstone samples and the number of freeze-thaw cycles under different chemical solution erosions.

During the freeze-thaw cycles from 0 to 60 times, the uniaxial compressive strengths in the neutral solution and alkaline solution decrease by $30.58 \%$ and $32.78 \%$, respectively. Under the acidic solution, the damage of sandstone samples is the biggest, and the uniaxial compressive strength decreases by $45.87 \%$. After 45 freeze-thaw cycles, the uniaxial compressive strength of the sandstone samples under acidic solution decreases with the increase in the number of freeze-thaw cycles, which indicates that the acidic solution has a great influence on the strength damage of the sandstone samples. After 45 freeze-thaw cycles, the sandstone samples have been totally eroded in the acidic solution.
Under the coupling action of chemical erosions and freezethaw cycles, the internal structure becomes sparse and loose. As a result, the mechanical properties are seriously deteriorated. The properties of rock damage under the coupling action of acidic solution erosion and freeze-thaw cycles are consistent with the results of Deng et al. [28].

3.1.4. Elastic Modulus. It can be seen from Figure 7 that the elastic modulus of the sandstone samples decreases with the increase in the number of freeze-thaw cycles. With the same freeze-thaw cycles, the elastic modulus under the acidic solution is the lowest, while the elastic modulus in the acidic solution is the highest.

Under the erosion of different chemical solutions, the elastic modulus decreases sharply in the freeze-thaw cycles between 0 and 15 and 45 and 60 times, which indicates that the initial freeze-thaw cycles and the 45 freeze-thaw cycles have a great influence on the grain structure of the sandstone. At this time, the particle damage is serious, and the connectivity of the sandstone samples is improved. The mechanical properties are seriously reduced. The influence of the number of freeze-thaw cycles on the change in sandstone elastic modulus is consistent with other research results, such as $\mathrm{Ni}$ et al. [7].

Under the condition of constant freeze-thaw cycles, deterioration of the elastic modulus in the acidic solution is the most serious. The elastic modulus in the neutral solution is higher than that in the alkaline solution. And the relationships between the elastic modulus of sandstone samples and the number of freeze-thaw cycles under neutral solution and alkaline solution are basically the same. In the interval of 0-60 cycles of freeze-thaw, the elastic modulus of sandstone samples decreases by $31.83 \%$ in the acidic solution, while the decreases are $23.31 \%$ and $26.20 \%$ in the neutral and alkaline 


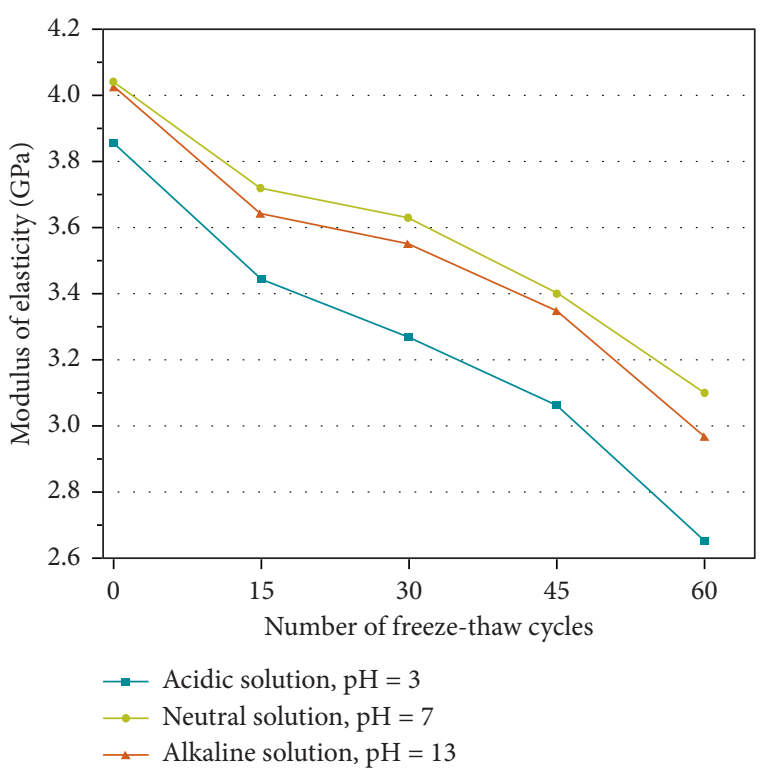

Figure 7: Relationship curves of elastic modulus and number of freeze-thaw cycles of sandstone samples under different chemical solution erosions.

solutions, indicating that the acidic solution has a great influence on the deterioration of the elastic modulus of sandstone.

3.2. TCT Results and Discussion. In this chapter, based on the results of UCT, the effects of different confining pressures on the mechanical properties of yellow sandstone under the coupling action of chemical erosion and freeze-thaw cycles are analyzed.

When the confining pressure is fixed, the stress-strain curves under TCT are basically the same as that under UCT, which all experience the compression, elastic, plastic, and failure stages. Combined with the stress-strain curves under UCT, it is found that the stress-strain curves under TCT have a certain delay after the peak value, and the plastic characteristics are more obvious. Therefore, the stress-strain curves under TCT are not further described.

3.2.1. Compressive Strength. In Figure 8, it can be seen that the compressive strengths of the sandstone samples increase with the increase in the confining pressure with the same freeze-thaw cycles and in the same chemical solution [29]. Compared with the uniaxial compressive strength, the compressive strength under $3 \mathrm{MPa}$ confining pressure has a rapid increase. When the confining pressure rises from $3 \mathrm{MPa}$ to $6 \mathrm{MPa}$, the compressive strength of the sandstone samples increases; however, the increase is smaller.

In Figure 9, under $3 \mathrm{MPa}$ confining pressure, the gradient of the slope of the curves decreases seriously after 45 cycles of freeze-thaw, which is consistent with the corresponding curves variation under UCT. Compared with the sandstone samples without freeze-thaw cycles, the compressive strength of sandstone samples after 60 freeze-thaw cycles under acidic solution decreases by $28.89 \%$ and by

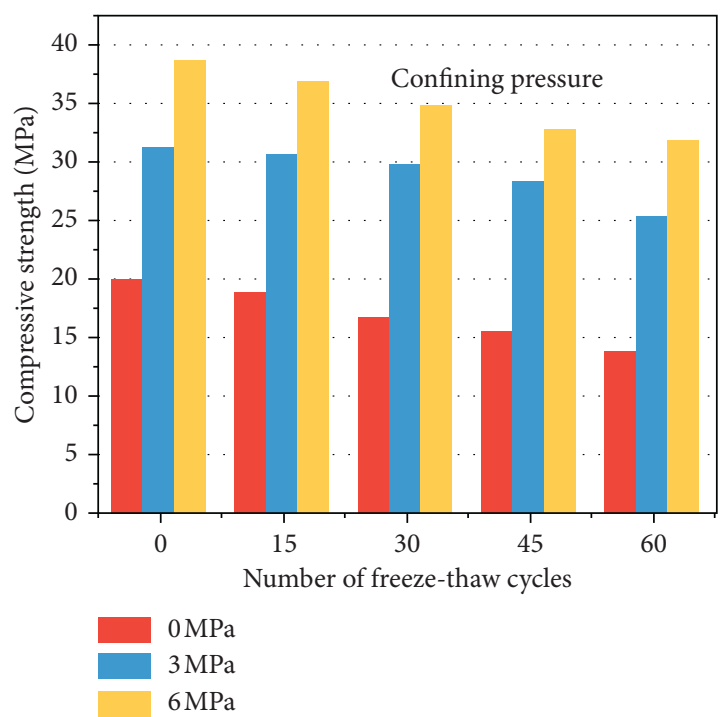

Figure 8: The relationship between compressive strength and the number of freeze-thaw cycles in uniaxial compression tests and peri-pressures of 3 and $6 \mathrm{MPa}$, respectively.

$19.57 \%$ and $19.77 \%$ in the neutral solution and alkaline solution, respectively. Under the confining pressure of $6 \mathrm{MPa}$, the largest reduction of compressive strength is observed in the initial 15 cycles of freeze-thaw. During the freeze-thaw cycles from 0 to 60 times, the confining pressure in the acidic solution decreases by $18.81 \%$ and by $18.16 \%$ and $18.71 \%$ in the neutral solution and alkaline solution, respectively. It can be seen that the increase in confining pressure reduces the degree of attenuation of the compressive strength.

The exponential fitting curves of the triaxial compressive strength and the number of freeze-thaw cycles are obtained (Figure 9).

It can be seen from Figure 9 and the above formulas that the compressive strength of the sandstone samples in the three chemical solutions decreases exponentially with the increase in the number of freeze-thaw cycles. Under the confining pressure of $3 \mathrm{MPa}$, the slope of the curve increases continuously. According to Figure 7, the reason is that the chemical erosions and freeze-thaw cycles have more influence on the compressive strength of the sandstone samples than the confining pressure. Under the confining pressure of $6 \mathrm{MPa}$, as the number of freeze-thaw cycles increases, the slope of the curve decreases, and the influence of confining pressure on the compressive strength of sandstone samples dominates.

3.2.2. Elastic Modulus. The relationships between the elastic modulus of the sandstone samples and the number of freezethaw cycles under different chemical solutions are plotted by exponential fitting (Figure 10). Under the same chemical solution erosion, the elastic modulus of the sandstone samples under different confining pressures gradually decreases with the increase in the number of freeze-thaw cycles. Under the same confining pressure and freeze-thaw 


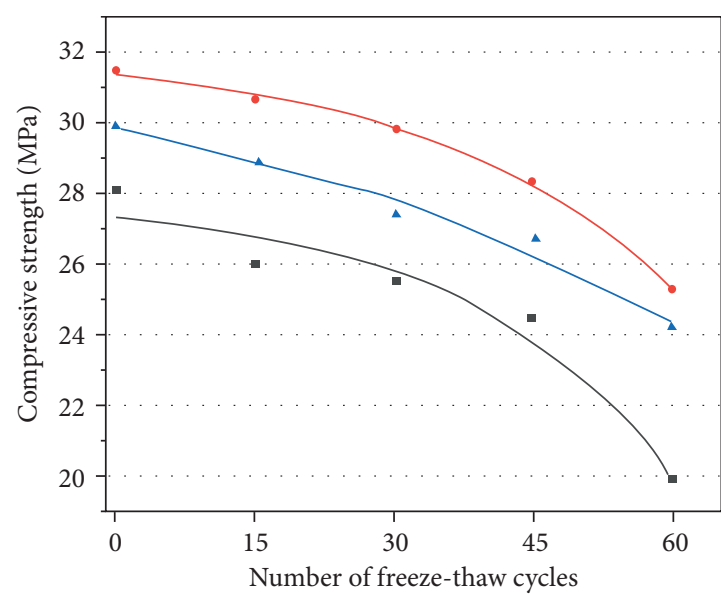

- Acidic solution, $\mathrm{pH}=3$

- Neutral solution, $\mathrm{pH}=7$

Alkaline solution $\stackrel{\mathrm{pH}}{\mathrm{p}}=13$
- $S=27.929-0.554$ $\exp (0.044 \mathrm{~m}), R^{2}=0.902$

$-S=32.173-0.738$ $\exp (0.037 \mathrm{~m}), R^{2}=0.995$

$-S=31.664-2.808$ $\exp (0.018 \mathrm{~m}), R^{2}=0.958$

(a)

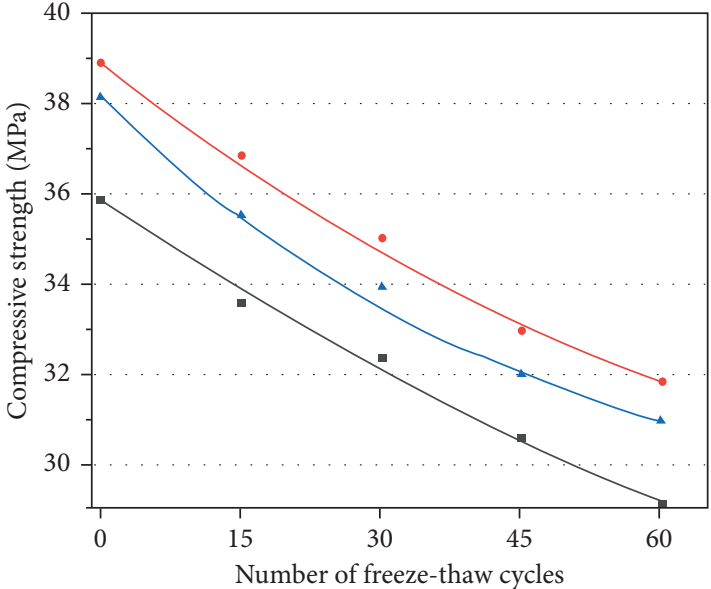

- Acidic solution $\mathrm{pH}=3$

- Neutral solution, $\mathrm{pH}=7$

Alkaline solution, $\mathrm{pH}=13$

$$
\begin{aligned}
& S=18.805+17.047 \\
& \quad \exp (-0.008 \mathrm{~m}), R^{2}=0.988 \\
& -S=26.590+12.386 \\
& \quad \exp (-0.014 \mathrm{~m}), R^{2}=0.984 \\
& -\quad S=28.137+10.061 \\
& \quad \exp (-0.021 \mathrm{~m}), R^{2}=0.989
\end{aligned}
$$

(b)

FIGURE 9: Curves of compressive strength and number of freeze-thaw cycles of sandstone samples under different chemical erosions: (a) compressive strength curves at a confining pressure of $3 \mathrm{MPa}$; (b) compressive strength curves at a confining pressure of $6 \mathrm{MPa}$. $S$ is the compressive strength of the sandstone samples subjected to $m$ times freeze-thaw cycles under different chemical solutions. $R^{2}$ is the correlation coefficient.

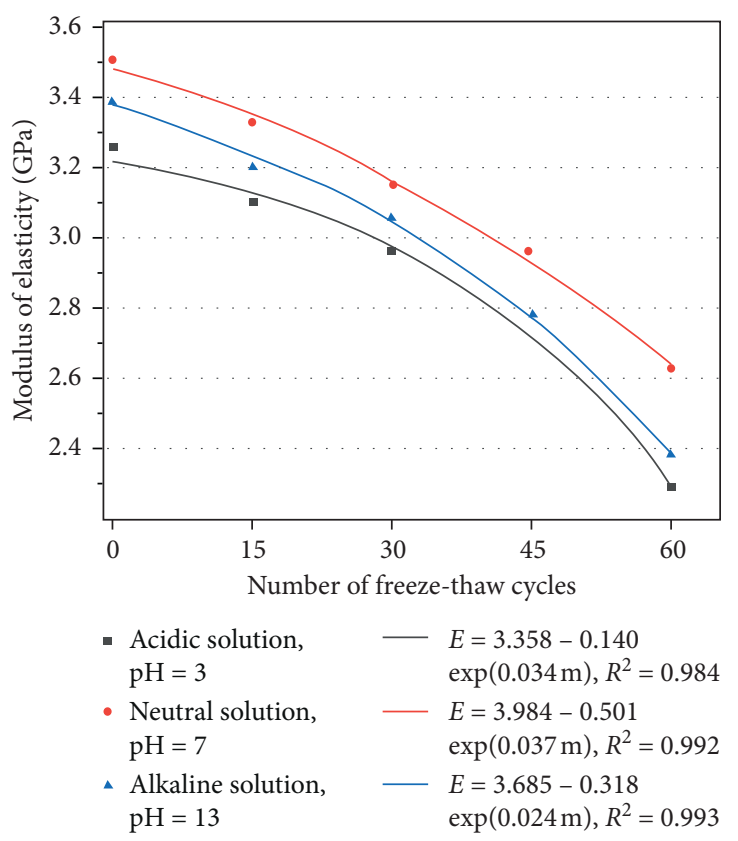

(a)

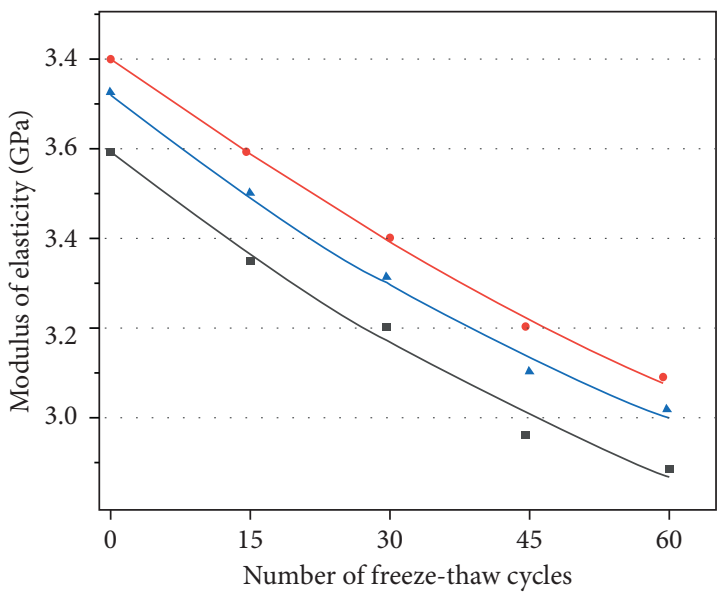

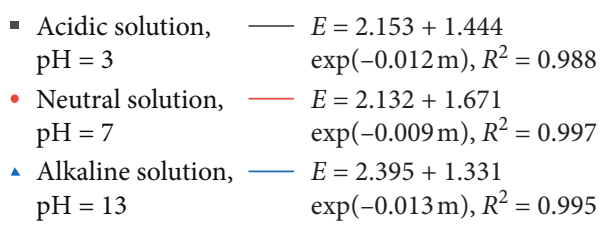

(b)

FIGURE 10: Fitting curves of elastic modulus of sandstone samples and number of freeze-thaw cycles under different chemical erosions: (a) the elastic modulus curves under a confining pressure of $3 \mathrm{MPa}$; (b) the elastic modulus curves under a confining pressure of $6 \mathrm{MPa}$. $E$ is the elastic modulus of the samples subjected to $m$ times freeze-thaw cycles under different chemical solution. $R^{2}$ is the correlation coefficient. 
cycles, the elastic modulus of the sandstone samples in the acidic solution is the lowest, while it is the largest in the neutral solution. Under the same chemical solution erosion and freeze-thaw cycles, the elastic modulus of the sandstone samples increases correspondingly with the increase in confining pressure. Under the confining pressure of $3 \mathrm{MPa}$, the elastic modulus of the sandstone samples under the erosion of three chemical solutions decrease in increasing speed after 45 cycles of freeze-thaw cycles. Under the confining pressure of $6 \mathrm{MPa}$, in the $0-15$ cycles of freezethaw, the elastic modulus of sandstone samples under the erosion of different chemical solutions witness the largest decrease. It can be seen that the elastic modulus of the sandstone samples under the three chemical solution decreases exponentially with the increase in the number of freeze-thaw cycles.

3.2.3. Analysis of Cohesion Strength and Internal Friction Angle. The Mohr-Coulomb criterion indicates that all the stress circles in the triaxial tests are approximately tangent to a straight line. The stress value of the tangent point represents the normal stress $\sigma$ and the shear stress $\tau$ on the fracture surface. However, in practical applications, the best tangent line cannot be selected on the stress circle curve. According to the Experiment Course on Rock Mechanics [30], with $\sigma_{3}$ as the independent variable and $\sigma_{1}$ as the dependent variable, and the regression equation is determined by the least squares method:

$$
\begin{aligned}
\sigma_{1} & =a+b \sigma_{3}, \\
\varphi & =\sin ^{-1} \frac{b-1}{b+1}, \\
C & =a \frac{1-\sin \varphi}{2 \cos \varphi},
\end{aligned}
$$

where $\varphi$ is the internal friction angle $\left({ }^{\circ}\right)$ and $\mathrm{C}$ is the cohesion strength of the sandstone $(\mathrm{MPa})$.
The internal friction angle and cohesion strength are calculated according to formula (2), and the result is shown in Table 3.

According to Table 3 and Figure 11, the internal friction angle of the sandstone samples fluctuates around $30^{\circ}$ under the coupling action of chemical solution erosion and freezethaw cycles. In the same chemical solution, the cohesion strength of the sandstone samples increases with the increase in the number of freeze-thaw cycles. Under the same number of freeze-thaw cycles, the cohesive strength of the sandstone samples in the acidic solution is the smallest, while it is the largest in the neutral solution. During the first 60 cycles of freeze-thaw, the cohesive strength of the sandstone samples decreases by $35.4 \%, 27.2 \%$, and $29.3 \%$ in the acid, neutral, and alkaline solutions, respectively. During the 45-60 cycles of freeze-thaw, the curve has the largest decline, which indicates that the acidic solution has the most obvious influence on the sandstone samples. The internal damage of sandstone is intensified after 45 cycles of freezethaw, and the mechanical properties are seriously deteriorated.

\section{Damage Mechanism of Chemical Erosion and Freeze-Thaw Cycles}

4.1. Analysis of Chemical Erosion Damage. The fine-grained yellow sandstone samples react differently in different chemical solutions. During the test, the chemical reaction of sandstone samples in acidic solution is more intense than that in the neutral and alkaline solutions. The chemical interaction of water-rock not only changes the composition of the sandstone samples but also leads to the formation of pores and microcracks in the rock [29].

The following chemical reactions occur between carbonate, quartz, cementitious minerals, and chemical solutions. The reaction pattern of the samples in an acidic $\mathrm{H}_{2} \mathrm{SO}_{4}$ $(\mathrm{pH}=3,0.01 \mathrm{~mol} / \mathrm{L})$ solution is as follows:

$$
\begin{aligned}
\mathrm{Ca}\left(\mathrm{AlSi}_{3} \mathrm{O}_{8}\right)_{2}+2 \mathrm{H}^{+}+\mathrm{H}_{2} \mathrm{O} & \longrightarrow \mathrm{Ca}^{2+}+4 \mathrm{SiO}_{2}+\mathrm{Al}_{2}\left(\mathrm{Si}_{2} \mathrm{O}_{5}\right)(\mathrm{OH})_{4} \downarrow \\
\mathrm{NaAlSi}_{3} \mathrm{O}_{8}+4 \mathrm{H}^{+}+4 \mathrm{H}_{2} \mathrm{O} & \longrightarrow \mathrm{Na}^{+}+\mathrm{Al}^{3+}+3 \mathrm{H}_{4} \mathrm{SiO}_{4} \\
\mathrm{CaCO}_{3}+2 \mathrm{H}^{+} & \longrightarrow \mathrm{Ca}^{2+}+\mathrm{H}_{2} \mathrm{O}+\mathrm{CO}_{2} \uparrow
\end{aligned}
$$

The reaction pattern of the samples in the neutral $\mathrm{NaCl}$ $(\mathrm{pH}=7)$ solution is as follows:

$$
\begin{aligned}
\mathrm{NaAlSi}_{3} \mathrm{O}_{8}+8 \mathrm{H}_{2} \mathrm{O} & \longrightarrow \mathrm{Na}^{+}+\mathrm{Al}(\mathrm{OH})_{4}^{-}+3 \mathrm{H}_{4} \mathrm{SiO}_{4}, \\
\mathrm{SiO}_{2}+2 \mathrm{H}_{2} \mathrm{O} & \longrightarrow \mathrm{H}_{4} \mathrm{SiO}_{4},
\end{aligned}
$$

The reaction pattern of the samples in an alkaline $\mathrm{NaOH}$ $(\mathrm{pH}=13,0.01 \mathrm{~mol} / \mathrm{L})$ solution is as follows:

$$
\begin{aligned}
\mathrm{NaAlSi}_{3} \mathrm{O}_{8}+6 \mathrm{OH}^{-}+2 \mathrm{H}_{2} \mathrm{O} & \longrightarrow \mathrm{Na}^{+}+\mathrm{Al}(\mathrm{OH})_{4}^{-}+3 \mathrm{H}_{2} \mathrm{SiO}_{4}^{2-} \\
\mathrm{SiO}_{2}+2 \mathrm{H}_{2} \mathrm{O} & \longrightarrow \mathrm{H}_{4} \mathrm{SiO}_{4} \\
\mathrm{SiO}_{2}+2 \mathrm{OH}^{-} & \longrightarrow \mathrm{SiO}_{3}^{2-}+\mathrm{H}_{2} \mathrm{O}
\end{aligned}
$$

In the acidic solution, anorthite, albite, and other calcareous cement release a large amount of $\mathrm{Ca}^{2+}, \mathrm{Na}^{+}$, and $\mathrm{Al}^{3+}$, and the chemical reaction of water-rock is intense. A large amount of particulate compounds dissolve into free 
TABLE 3: Internal friction angle and cohesion strength of sandstone samples under the coupling action of chemical solution erosion and freeze-thaw cycles.

\begin{tabular}{|c|c|c|c|c|}
\hline Chemical solution & Number of freeze-thaw cycles & Internal friction angle $\left({ }^{\circ}\right)$ & Cohesion strength $(\mathrm{MPa})$ & $R^{2}$ \\
\hline \multirow{5}{*}{ Acid solution } & 0 & 32.09 & 5.00 & 0.982 \\
\hline & 15 & 30.11 & 4.60 & 0.983 \\
\hline & 30 & 30.31 & 4.28 & 0.979 \\
\hline & 45 & 28.77 & 4.23 & 0.973 \\
\hline & 60 & 32.37 & 3.23 & 0.996 \\
\hline \multirow{5}{*}{ Neutral solution } & 0 & 30.96 & 5.91 & 0.971 \\
\hline & 15 & 29.94 & 5.75 & 0.969 \\
\hline & 30 & 30.82 & 5.25 & 0.936 \\
\hline & 45 & 28.90 & 4.95 & 0.933 \\
\hline & 60 & 29.79 & 4.30 & 0.977 \\
\hline \multirow{5}{*}{ Alkaline solution } & 0 & 30.12 & 5.87 & 0.994 \\
\hline & 15 & 29.20 & 5.52 & 0.982 \\
\hline & 30 & 30.39 & 4.75 & 0.974 \\
\hline & 45 & 28.83 & 4.70 & 0.951 \\
\hline & 60 & 29.24 & 4.15 & 0.984 \\
\hline
\end{tabular}

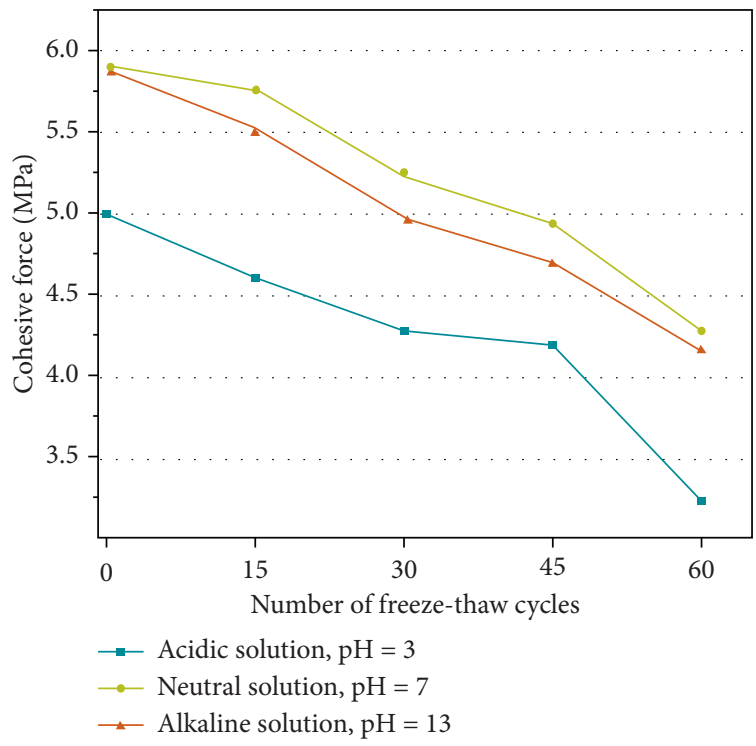

FIgURE 11: Curve of the number of freeze-thaw cycles and cohesion between different chemical solutions.

ions, which promote the softening of sample particles and leads to an increase in porosity and a decrease in rock mechanical properties. In the neutral solution, the reaction of water-rock is slow and only the mineral hydrolysis occurs. In the alkaline solution, only the dissolution of quartz and the hydrolysis reaction of feldspar happen. The water-rock reaction is less severe to that in the acidic solution.

4.2. Analysis of Freeze-Thaw Cycles Damage. The thermosphysical properties of the three-phase medium of rock, water, and ice during freeze-thaw cycles are the main causes of freeze-thaw cycles damage of sandstone samples. Before the freezing process, existing openings in the sandstone are filled with confined water, as shown in Figure 12-(a). During the freezing process, shrinkage occurs between the rock particles. Due to the different material properties and aggregation level, the shrinkage is not uniform, and friction and extrusion between the particles lead to the frost heave force, which causes secondary opening. Besides, as the confined water ices, residual confined water is squeezed into cracks and leads to increased secondary opening, as shown in Figure 12-(b). Then, during the thawing process, the ice in the pores in the rock thaws, and the thawed water enters the micropores [31], which resulted in the expansion of the original pores. As the number of freeze-thaw cycles increases, the internal frost heave force is continuously generated and released, causing increasing damage until the failure of sandstone samples. The freezing direction of the samples extends from the surface to the inside, and the formation of the frost heaving force leads to an increase in the pore volume. 


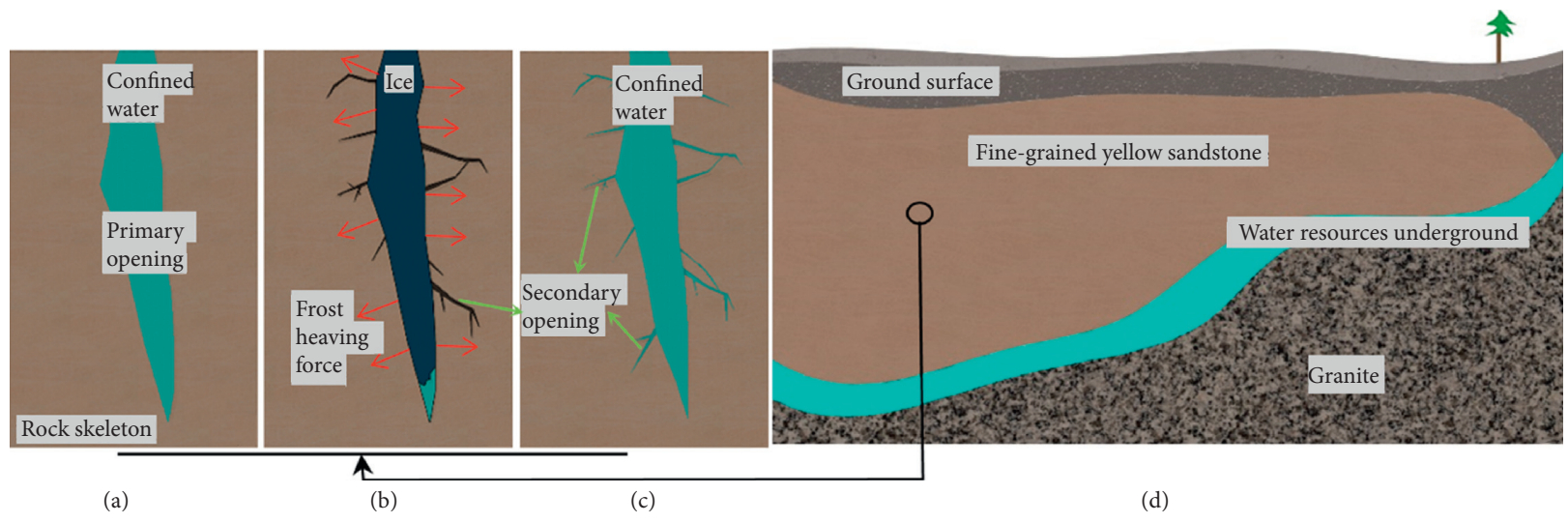

Figure 12: Schematic diagram of freeze-thaw cycle.

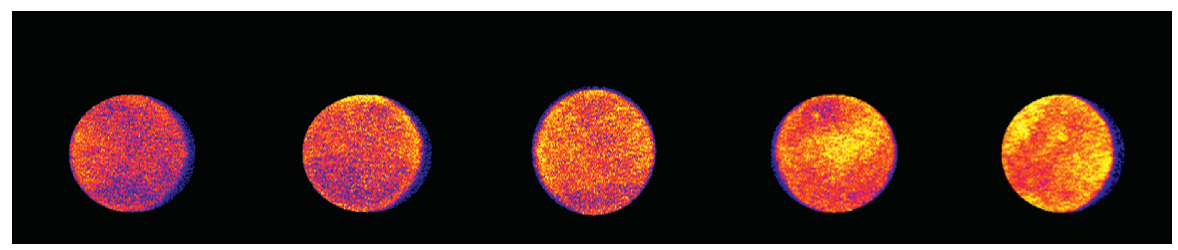

(a)

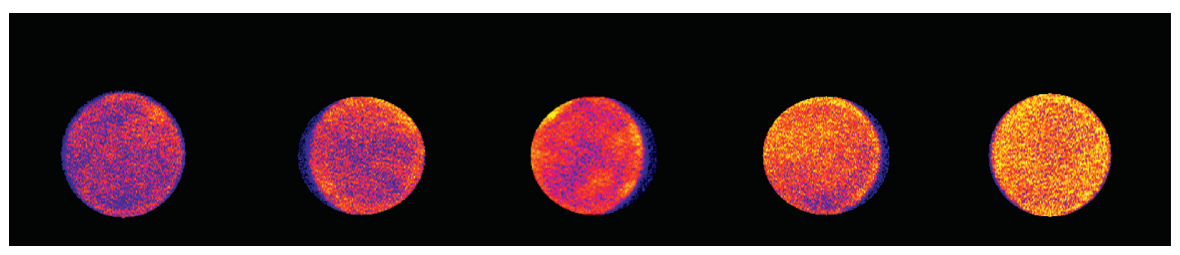

(b)

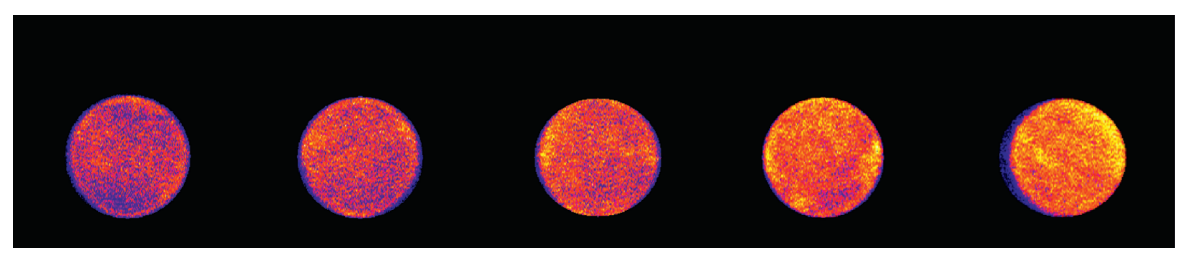

(c)

FIGURE 13: Magnetic resonance images of sandstone samples after different chemical solution erosion and freeze-thaw cycles: (a) images of sandstone samples under acidic solution (from left to right: freeze-thaw cycles are $0,15,30,45$, and 60, respectively); (b) images of sandstone samples under neutral solution (from left to right: freeze-thaw cycles are $0,15,30,45$, and 60 , respectively); (c) images of sandstone samples under alkaline solution (from left to right: freeze-thaw cycles are $0,15,30,45$, and 60 , respectively).

When the inside pore connects, the mechanical properties of rock mass are seriously deteriorated.

\subsection{Sandstone Damage Mechanism under Chemical Freezing- Thawing Coupling. The magnetic resonance imaging of the sandstone samples under the coupling action of the chemical solution erosion and the freeze-thaw cycle is carried out [32]. Observations are conducted on the cross section at $1 / 3$ height along the axial direction of the sandstone samples, and the corresponding nuclear magnetic resonance imaging images are shown in Figure 13. A high density of hydrogen nucleus may indicate larger and denser pores. Both the pore}

size and distribution are important parameters of porous media which defines the macroscopic properties of the media [33].

It can be seen from Figures 13 and 14 that the density of hydrogen nucleus in the sandstone samples increases with the increase in the number of freeze-thaw cycles, which indicates that the internal compactness of the samples becomes loose with the increase in freeze-thaw cycles and a large number of pores and large voids form. The hydrogen nucleus density on the cross section surface is higher than that in the interior, indicating that the rock damage is developed from the surface to the inside. After 45 cycles of 


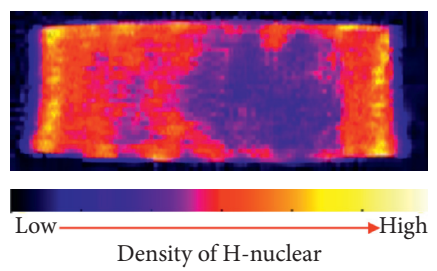

(a)

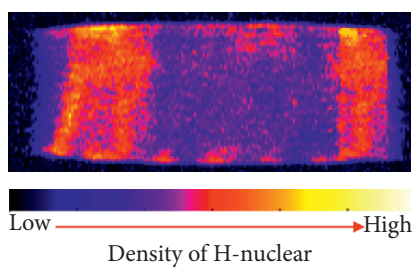

(b)

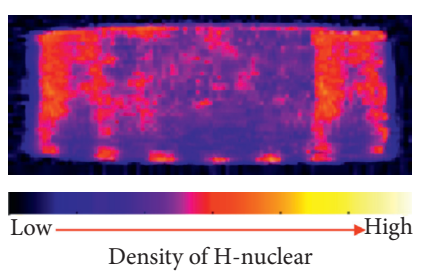

(c)

FIGURE 14: Coronal map of nuclear magnetic imaging of rock samples eroded by different chemical solutions: (a) acid erosion; (b) alkaline erosion; (c) neutral erosion.

freeze-thaw, the bright spot area increases significantly, and the damage inside the sandstone increases. After 60 cycles of freeze-thaw, the bright spot area covers almost the entire cross section, indicating that the internal freeze-thaw damage of the sample is serious. Under constant freeze-thaw cycles, the hydrogen nucleus density on the cross section is the largest in the acidic solution, while it is the lowest in the neutral solution. This shows that the most serious damage to the internal structure of the sandstone samples occurs in the acidic solution, which produces the largest number of pores. The damage of the samples under the alkaline solution is slightly higher than that in the neutral solution.

During the freeze-thaw cycles, the internal pores of the sandstone samples expand and connect, which promotes the erosion of chemical solutions and the migration of water from the surface and the inside; this, in turn, leads to the expansion of pores and increasing water content in the sandstone samples. Therefore, when the pores are frozen again, the internal frost heave force increases correspondingly and causes severe damage. Therefore, the rock damage is the combined result of chemical solution erosion and the freezethaw cycles.

\section{Conclusions}

In this paper, laboratory experiments were carried out on fine-grained yellow sandstone collected in underground mines in Zigong, China. The mechanical parameters and damage properties of yellow sandstone samples under chemical erosion and freeze-thaw cycles are analyzed. The main conclusions are as follows:

(1) The compressive strength and elastic modulus of the sandstone samples in three chemical solutions decrease with the increase in freeze-thaw cycles. Under constant freeze-thaw cycles, the damage of mechanical properties in the acidic solution is the most serious, while it is less obvious in the neutral solution.

(2) The compressive strength and elastic modulus of sandstone samples under different confining pressures decrease in an exponential trend with increasing freeze-thaw cycles. The overall slope of the curve increases under $3 \mathrm{MPa}$ confining pressures. Under the confining pressure of $6 \mathrm{MPa}$, the slope of the curve is continuously reduced, and the influence of chemical solution erosion and freeze-thaw cycles on the mechanical properties of the rock is reduced, while the confining pressure plays a dominant role.

(3) The internal friction angle of the sandstone samples under the coupling action of the chemical solution erosion and the freeze-thaw cycles fluctuates around $30^{\circ}$; the cohesive strength gradually decreases as the number of freeze-thaw cycles increases. After 45 cycles of freeze-thaw, the decay rate increases, and the cohesive strength of the sandstone samples decreases by $35.4 \%$ in the acidic solution and decreases by $27.2 \%$ and $29.3 \%$ in the neutral and alkaline solutions, respectively.

(4) Magnetic resonance imaging shows that the rock damage by chemical solution erosion and freezethaw cycles develops from surface to interior. During the 45-60 cycles of freeze-thaw, the connectivity among the rock particles becomes better and the mechanical properties are seriously deteriorated.

(5) In the acidic solution, the chemical reaction of the rock sample minerals is the most severe, and the mechanical properties are most seriously deteriorated. The damage in the alkaline solutions is less obvious, while only hydrolysis reaction occurs in the neutral solution. During the freeze-thaw cycles, the formation of frost heave forces leads to the expansion of the pores inside the sandstone samples, which promotes the erosion of chemical solutions. Therefore, the chemical solution erosion and the freezethaw cycles promote each other and affect the damage degree of the rock together.

\section{Data Availability}

The data used to support the findings of this study are available from the corresponding author upon request.

\section{Conflicts of Interest}

The authors declare that there are no conflicts of interest regarding the publication of this paper.

\section{Acknowledgments}

This work was supported by the National Natural Science Foundation of China (51674149), the Natural Science Foundation of Shandong Province (ZR2018PEE005), the 
Research Fund of the State Key Laboratory of Coal Resources and Safe Mining (SKLCRSM19KF015 and SKLCRSM20KF006), and the Research Fund of the Key Laboratory of Mine Disaster Prevention and Control of the Ministry of Education (MDPC201915).

\section{References}

[1] S. Chen, T. Jiang, H. Wang, F. Feng, D. Yin, and X. Li, "Influence of cyclic wetting-drying on the mechanical strength characteristics of coal samples: a laboratory-scale study," Energy Science \& Engineering, vol. 7, no. 6, pp. 3020-3037, 2019.

[2] S. Demirdag, "Effects of freezing-thawing and thermal shock cycles on physical and mechanical properties of filled and unfilled travertines," Construction and Building Materials, vol. 47, pp. 1395-1401, 2013.

[3] J. Martinez-Martinez, D. Benavente, M. Gomez-Heras, L. Marco-Castano, and M. A. Garcia-del-Cura, "Non-linear decay of building stones during freeze-thaw weathering processes," Construction \& Building Materials, vol. 38, pp. 443-454, 2013.

[4] F. S. Rostásy, R. Weiß, and G. Wiedemann, "Changes of pore structure of cement mortars due to temperature," Cement \& Concrete Research, vol. 10, pp. 157-164, 1980.

[5] L. Wen, L. I. Xibing, Y. Yin, and L. Gao, "Study of physicomechanical properties of granite porphyry and limestone in slopes of open-pit metal mine under freezing-thawing cycles and their application," Journal of Glaciology \& Geocryology, vol. 36, pp. 632-639, 2014.

[6] Y.-Y. Cai, J. Yu, G.-F. Fu, and H. Li, "Experimental investigation on the relevance of mechanical properties and porosity of sandstone after hydrochemical erosion," Journal of Mountain Science, vol. 13, no. 11, pp. 2053-2068, 2016.

[7] X. Ni, X. Shen, and Z. Zhu, "Microscopic characteristics of fractured sandstone after cyclic freezing-thawing and triaxial unloading tests," Advances in Civil Engineering, vol. 2019, Article ID 6512461, 11 pages, 2019.

[8] L. P. Wang, N. Li, J. L. Qi, Y. Z. Tian, and S. H. Xu, "A study on the physical index change and triaxial compression test of intact hard rock subjected to freeze-thaw cycles," Cold Regions Science and Technology, vol. 160, pp. 39-47, 2019.

[9] C. Park, J. H. Synn, H. S. Shin, D. S. Cheon, H. D. Lim, and S. W. Jeon, "Experimental study on the thermal characteristics of rock at low temperatures," International Journal of Rock Mechanics and Mining Sciences, vol. 41, pp. 81-86, 2004.

[10] R. Altindag, I. S. Alyildiz, and T. Onargan, "Mechanical property degradation of ignimbrite subjected to recurrent freeze-thaw cycles," International Journal of Rock Mechanics and Mining Sciences, vol. 41, no. 6, pp. 1023-1028, 2004.

[11] M. Feuer and I. Ince, "Effects of the freeze-thaw (F-T) cycle on the andesitic rocks (Sille-Konya/Turkey) used in construction building," Journal of African Earth Sciences, vol. 109, pp. 96-106, 2015.

[12] M. H. Ghobadi and R. Babazadeh, "Experimental studies on the effects of cyclic freezing-thawing, salt crystallization, and thermal shock on the physical and mechanical characteristics of selected sandstones," Rock Mechanics and Rock Engineering, vol. 48, no. 3, pp. 1001-1016, 2015.

[13] A. Momeni, Y. Abdilor, G. R. Khanlari, M. Heidari, and A. A. Sepahi, "The effect of freeze-thaw cycles on physical and mechanical properties of granitoid hard rocks," Bulletin of Engineering Geology and the Environment, vol. 75, no. 4, pp. 1649-1656, 2016.
[14] J. Yu, X. Chen, H. Li et al., "Effect of freeze-thaw cycles on mechanical properties and permeability of red sandstone under triaxial compression," Journal of Mountain Science, vol. 12, no. 1, pp. 218-231, 2015.

[15] H. Li, K. I.-I. Eshiet, Y. Sheng, Z. Zhong, X. Liu, and D. Yang, "A parallel-bonded chemical corrosion model for discrete element modelling of chemically corroded limestone," Engineering Fracture Mechanics, vol. 202, pp. 297-310, 2018.

[16] T. Han, J. Shi, Y. Chen, and X. Cao, "Quantifying microstructural damage of sandstone after hydrochemical corrosion," International Journal of Geomechanics, vol. 18, no. 10, Article ID 04018121, 2018.

[17] X.-T. Feng, S. Chen, and H. Zhou, "Real-time computerized tomography (CT) experiments on sandstone damage evolution during triaxial compression with chemical corrosion," International Journal of Rock Mechanics and Mining Sciences, vol. 41, no. 2, pp. 181-192, 2004.

[18] T. Han, J. Shi, Y. Chen, and Z. Li, "Effect of chemical corrosion on the mechanical characteristics of parent rocks for nuclear waste storage," Science and Technology of Nuclear Installation, vol. 2016, Article ID 7853787, 11 pages, 2016.

[19] B. K. Atkinson and P. G. Meredith, "Stress corrosion cracking of quartz: a note on the influence of chemical environment," International Journal of Rock Mechanics \& Mining Sciences \& Geomechanics Abstracts, vol. 19, p. 24, 1982.

[20] J. Zhang, H. Deng, A. Taheri, B. Ke, C. Liu, and X. Yang, "Degradation of physical and mechanical properties of sandstone subjected to freeze-thaw cycles and chemical erosion," Cold Regions Science and Technology, vol. 155, pp. 37-46, 2018.

[21] C. C. Chen, S. J. Peng, S. K. Wu, and J. Xu, "The effect of chemical erosion on mechanical properties and fracture of sandstone under shear loading: an experimental study," Scientific Reports, vol. 9, no. 1, 2019.

[22] C. Xu, Y. Chen, S. Wang, A. Javadi, X. Du, and R. Azzam, "Mechanical properties of tonalite subjected to combined effects of chemical corrosion and freeze-thaw cycles," Applied Sciences, vol. 9, no. 18, p. 3890, 2019.

[23] Ministry of Housing and Urban-Rural Construction of the People's Republic of China and General Administration of Quality Supervision, Inspection and Quarantine of the People's Republic of China, Standard for Test Methods of Engineering Rock Mass, China Planing Press, Beijing, China, 2013, in Chinese.

[24] Changjiang River Scientific Research Institute, Ministry of Water Resources of the People's Republic of China, Specifications for Rock Tests in Water Conservancy and Hydroelectric Engineering, China Water \& Power Press, Beijing, China, 2001, in Chinese.

[25] J. Yu, X. Chen, Y.-Y. Cai, and H. Li, “Triaxial test research on mechanical properties and permeability of sandstone with a single joint filled with gypsum," KSCE Journal of Civil Engineering, vol. 20, no. 6, pp. 2243-2252, 2016.

[26] L. Qiu, D. Song, X. He et al., "Multifractal of electromagnetic waveform and spectrum about coal rock samples subjected to uniaxial compression," Fractals, vol. 28, no. 4, Article ID 2050061, 2020.

[27] B. Ke, J. Zhang, H. Deng, and X. Yang, "Dynamic characteristics of sandstone under coupled static-dynamic loads after freeze-thaw cycles," Applied Sciences, vol. 10, no. 10, p. 3351, 2020.

[28] H. Deng, S. Yu, and J. Deng, "Damage characteristics of sandstone subjected to coupled effect of freezing-thawing 
cycles and acid environment," Advances in Civil Engineering, vol. 2018, Article ID 3560780, 10 pages, 2018.

[29] G. Lu, X. Feng, Y. Li, and X. Zhang, "Influence of microwave treatment on mechanical behaviour of compact basalts under different confining pressures," Journal of Rock Mechanics and Geotechnical Engineering, vol. 12, no. 2, pp. 213-222, 2020.

[30] Z. Fu, F. Xiao, Y. Liu, and S. Chen, Experiment Course on Rock Mechanics, Chemical Industry Press, Beijing, China, 2011, in Chinese.

[31] G. Wang, C. H. Jiang, J. N. Shen et al., "Deformation and water transport behaviors study of heterogenous coal using CT-based 3D simulation," International Journal of Coal Geology, vol. 211, Article ID 103204, 2019.

[32] Y. Shen, Y. Wang, X. Wei, H. Jia, and R. Yan, "Investigation of the meso-debonding process induced by freeze-thaw cycles at the sandstone-concrete interface using NMR technology," Construction \& Building Materials, vol. 214, Article ID 118962, 2020.

[33] G. Wang, J. N. Shen, S. M. Liu et al., "Three-dimensional modeling and analysis of macro-pore structure of coal using combined X-ray CT imaging and fractal theory," International Journal of Rock Mechanics and Mining Sciences, vol. 123, Article ID 104082, 2019. 